\title{
O discurso cronístico como espaço de tensão no discurso jornalístico ${ }^{1}$
}

Vanise Gomes de Medeiros *

\section{Resumo}

Este texto trata do papel da crônica no espaço do jornal como um lugar de significação, com autoria assumida e em constante tensão com a informação, pois pode romper com as ilusões de transparência do discurso jornalístico ao utilizar recursos como a ironia, a paródia, o ridículo.

Palavras-chave: crônica, discurso jornalístico, verdade.

\section{O tempo da crônica}

"Já passou o tempo em que o tempo não contava", diz Benjamim (1987) em seu ensaio "O narrador". É tendo como pano de fundo a mudança da noção de tempo que Benjamim vai expondo sua reflexão sobre a morte da narrativa. Fruto de uma época em que o tempo tinha outras significâncias, a narrativa, forma ancorada na tradição oral, sucumbe quando tempo passa a significar produção, isto é, quando o tempo passa a ser cultivado, jogando com as palavras de Benjamim, pelo que pode ser abreviado. Segundo Benjamim, as narrativas permitiam um intercâmbio de experiências; por meio delas se atualizava um conhecimento de mundo ancorado na sabedoria cultivada com o tempo - este entendido como resultado da experiência ou da vivência. Com a entrada da imprensa, instrumento decisivo na consolidação da burguesia, destaca-se uma forma de comunicação, a informação ${ }^{2}$, cujo veículo maior seria o jornal. A crônica jornalística brasileira insere-se no espaço jornalístico; é seu produto. Como tal, nasceu. A crônica vive sob a égide do mito da informatividade (cf. MARIANI, 1998, p. 243) e por essa outra concepção de tempo. É, pois, a partir do espaço de inserção da crônica no discurso jornalístico que se pretende refletir sobre o discurso cronístico.

* Profa. Dra. da Universidade Estadual do Rio de Janeiro e PUC-RIO.

E-mail: vanisegm@bol.com.br

Comun. Inf., v. 7, n. 1, p.34-46, jan./jun. 2004 
A crônica, como seu nome denuncia, traz a marca do tempo: Chrónos, do grego. Não são poucos os teóricos e estudiosos que põem em relevo a sua marca temporal: é comumente destacado como uma de suas características o fato de ser produzida no tempo de feitura do jornal, isto é, no espaço de até um dia. Além do escasso tempo para sua realização, a sua permanência no espaço também teria duração medida: a de um jornal que no dia seguinte já estaria na lata de lixo. Sem tempo para amadurecer e com tempo marcado para "morrer", para muitos e durante muito tempo, a crônica foi, em função disso, considerada um "gênero menor", , ainda que produzida por escritores renomados como Machado de Assis e Mário de Andrade, para citar apenas dois deles. Só o tempo e com ele novas formas de pensar foram mudando seu estatuto.

Produto de um tempo já capitalista, para usar mais uma vez a metáfora do tempo, uma vez que produto do jornal, considero que a crônica representa um espaço de tensão no discurso jornalístico. A fim de expor a crônica como espaço tensão no discurso jornalístico é preciso, antes, observar a cisão que foi se constituindo no dizer entre formas de saber.

\section{A cisão entre ciência e literatura}

Em "Ler o arquivo hoje", Pêcheux nos fala da distância que se formou entre duas culturas ${ }^{4}$, a científica e a literária:

"Ao longo de toda uma história das idéias que vai do século XVIII ao século XX (...) essas duas culturas não pararam de se distanciar uma da outra, veiculando, cada uma, não somente suas esperanças e ilusões, como também suas manias e seus tabus, ignorando de uma maneira mais ou menos deliberada a própria existência da outra." (1997, p. 56)

Distância engendrada, conforme Pêcheux, por formas de leitura distintas, distantes e especializadas. Por formas de leitura autorizadas e não autorizadas. Essa divisão, que Pêcheux aponta no campo da leitura, é trabalhada por Orlandi (1990) no terreno da escrita. Segundo essa autora, a partir do século XVII tem-se duas palavras - "rapport" e "relation" - que vão pouco a pouco diferenciando a prática do "relato daquilo que alguém viu pessoalmente" (idem). A primeira vai se destinar a trabalhos técnico-científicos, e resulta, por exemplo, no relatório de Comun. Inf., v. 7, n. 1, p.34-46, jan./jun. 2004 
pesquisa; a segunda vai se destinar ao relato literário. São duas práticas que, conforme Orlandi, vão separando o que seria ficção ("relation", narrativa) do que seria ciência ("rapport", relatório). São duas práticas que vão "regularizando" o que constituiria um território da ciência, em oposição a um território do ficcional, e que vão formando e organizando os discursos, situando-os de cada lado do paradigma. Portanto, com Pêcheux (1997) observamos uma cisão que vai se efetuando no território da leitura; com Orlandi (1990), a separação que vai se articulando no terreno da escritura. Vinculada a essảs duas separações encontra-se, dentre outras coisas, a figura do autor, ou melhor, a constituição da figura do autor nesses dois territórios.

Autor literário e autor de ciência já não significavam duas práticas comuns na Idade Média. Conforme Foucault (1998, p.27), se para o discurso científico, a atribuição de um autor era fundamental, como "indicador de verdade", o mesmo não ocorria no discurso literário. A partir do século XVII, contudo, esse quadro começa a mudar. Paralelamente a um enfraquecimento da figura do autor de ciência temse o fortalecimento da autoria no discurso literário. Citamos Foucault : "todas as narrativas, todos os poemas, todos os dramas ou comédias que se deixava circular na Idade Média no anonimato ao menos relativo, eis que, agora, se lhes perguntam (e exigem que respondam) de onde vêm, quem os escreveu; pede-se que o autor preste contas da unidade de texto posta sob seu nome, pede-se-lhe que revele, ou ao menos sustente, o sentido oculto que os atravessa; pede-se-lhe que os articule com sua vida pessoal e suas experiências vividas, com a história real que os viu nascer." (1998, p. 27)

De anônimo, a figura singular no século XIX (SCHNEIDER, 1985, p. 35), o autor do texto considerado literário, não cessa de se mostrar com sua assinatura; assinatura que, diferentemente do que ocorreu com o autor de ciência, não funciona como "indicador de verdade", mas como indicador de posse. Já o autor de ciência, este desaparece nos laboratórios e equipes (ORLANDI, 1996, p.140). Voltemos à crônica.

A palavra crônicajá encontra uso na escrita medieval para se referir a "registro ou narração dos fatos e suas circunstâncias em sua ordenação cronológica"(NEVES, 1992). Essa forma de escrita vai sofrer no século $\mathrm{XIV}$, ao menos em língua portuguesa, umamudança significativa: o cronista medieval vai se transformar em historiador (COSTA LIMA, 1986). Comun. Inf., v. 7, n. 1, p.34-46, jan./jun. 2004 
Segundo Costa Lima (1986), em Crônica de D. João I, de Fernão Lopes, a concepção existente de cronista como compilador de fatos se vê ultrapassada pela concepção de "intérprete dos fatos". Mais do que "narrar", Fernão Lopes precisava, com tal crônica, legitimar um bastardo, Mestre de Avis, "vencedor em uma verdadeira guerra civil, onde se apoiara na ação do povo e na iniciativa de mercadores enriquecidos e opondo-se à posição tomada pela maioria da nobreza lusa", como Rei de Portugal, futuro D. João I. Daí a necessidade de "interpretação", de leitura autorizada:

"A crônica, por assim dizer, deixa de se escrever por si própria e passa a depender da interpretação de quem a assina. O cronista deixara de ser um coletor, para tornar-se um intérprete" (idem, 1986, p. 22).

E daí o historiador. O cronista medieval se transforma em historiador e a crônica medieval passa aser conhecida como "cronicões"(SOARES 2000, p. 64). Curiosa passagem que se efetiva pela prática da interpretação, por conseguinte, da leitura: de registro de fatos a discurso histórico. Eque permite observar o paradoxo do discurso histórico: um trabalho de interpretação (e de leitura) que se apaga como tal.

A noção de interpretação tem como um uso corrente a idéia de funcionar como um dado a mais no processo de leitura. Melhor explicando, haveria uma prática de leitura "literal" sobre a qual a interpretação indicaria um algo a mais, qual seja o advento de uma subjetividade. Auma leitura "neutra", dos "fatos em si", a interpretação se sobreporia como a marca de uma tomada de posição. Não é, entretanto, assim que funciona no campo teórico em que se situa este trabalho. Para a Análise de Discurso, a interpretação é uma relação necessária do sujeito com o mundo (cf. ORLANDI, 1996, p. 20). Se parte do princípio de que todos os sentidos são possíveis (dado o limite da história) e que dizer é significar, a interpretação passa a ser entendida como princípio de significação. Citando Orlandi, "não há sentido sem interpretação"(2001, p. 63); não há dizer sem injunção à interpretação; não há sujeito sem interpretação. Portanto, não há um "antes" em repouso, ao qual se acrescentaria uma interpretação. Não há, enfim, neutralidade em Análise de Discurso, ainda que, recuperando o exemplo da crônica medieval, se proceda a uma "simples" compilação

Comun. Inf., v. 7, n. 1, p.345-46, jan./jun. 2004 


\section{8}

de dados. Há, entretanto, dois tipos de gestos de interpretação: do sujeito comum e do analista. O gesto de interpretação do sujeito comum é apagado no próprio ato em que se dá (cf. ORLANDI, 1996, p.84), uma vez que aí joga o efeito de evidência, que nega a interpretação. Já o gesto de interpretação do analista apóia-se em um dispositivo teórico, que demarca uma posição de leitura outra em relação às demais teorias. Não há, portanto, "uma posição neutra do analista em relação aos sentidos" (idem, p. 85).

Pensando no caso de Fernão Lopes, o que se tem com seu trabalho é um gesto que inaugura uma nova prática: a prática histórica. Em outras palavras, com Fernão Lopes tem-se uma reorganização dos sentidos do cronista medieval - de "compilador" a "articulador"-, e em ambos se configura um duplo gesto de interpretação: do sujeito para dizer e do "analista" para com o que configura seu objeto de trabalho.

De acordo com Pêcheux (1997), o trabalho social da leitura (que se estende com Orlandi para o trabalho social da escrita) confere a alguns "o direito de produzir leituras originais, logo "interpretações" (p. 58; aspas do autor) e a outros "a tarefa subalterna de preparar e sustentar, pelos gestos anônimos do tratamento 'literal' dos documentos, as ditas 'interpretações" " (p. 58; aspas do autor). O que se pretende aqui destacar é que o discurso histórico traz em seu bojo a interpretação e foi, uma vez apagada a interpretação, se situando no paradigma do científico, porque foi se constituindo como "discurso da verdade". Uma observação importante: estou aqui considerando a noção de discurso histórico que vigorou durante boa parte de sua constituição até passar a ser, em meados do século XX, objeto de reflexão e discussão sobre seu lugar, seu modo de feitura, seus mitos, dentre outros aspectos. Retomando, então, a divisão exposta em Pêcheux, o que se pode observar é que o discurso histórico situa-se do lado daqueles que têm o direito à interpretação, à "leitura original" de que fala o autor.

Retornando à passagem do cronista medieval a historiador, o que se constata é que a "leitura original" se dá pela entrada do autor ${ }^{5}$ como voz legitimada para interpretar. Ou seja, a autoria funciona aí para sustentar um discurso como verdadeiro, como científico, ao mesmo tempo em que uma série de outras marcas, tais como as referências, as citações, o destaque da metodologia, da pesquisa e da documentação, o tratamento do que seriam os fatos como evidências, Comun. Inf., v. 7, n. 1, p.34-46, jan./jun. 2004 
independentemente da escritura, dentre outros, funcionam para apagar a existência da autoria e da interpretação. E trabalham, com isso, a ilusão da neutralidade. O que interessa destacar é que essa prática discursiva do discurso histórico articula-se a partir de um paradoxo. Dada a cisão entre as duas culturas de que fala Pêcheux, o discurso histórico se supõe no paradigma do discurso científico, opera na ilusão de ser um discurso objetivo e sem marcas de subjetividade; no entanto, o gesto de interpretação, o trabalho do autor legitima seu discurso. Um discurso que julga não se assinar.

Se isso funcionou com o discurso histórico, não é o que se verifica com o discurso literário. Aí, a autoria, originária da transgressão (FOUCAULT,1998, p. 47), fruto de uma preocupação de ordem já jurídica - atribuir propriedade e controlar o plágio -, confere ao discurso literário o lugar oposto na cisão apontada por Pêcheux e Orlandi. Cabe agora refletir sobre o que ocorre com a crônica brasileira, uma vez que ela é produto do discurso jornalístico e fruto do trabalho do literato e/ ou do jornalista.

\section{A crônica como espaço de tensão}

A crônica jornalística brasileira começa a ser engendrada ainda no século XIX, ou mais especificamente, por volta de 1854. Cândido (1992), em seu conhecido artigo "A vida ao rés-do-chão", nos fala de seus primórdios: originária do folhetim, ocupando um espaço no pé da página, uma seção do jornal Correio Mercantil do Rio de Janeiro, denominada "Ao correr da pena", e assinada por um importante escritor brasileiro, José de Alencar, começa a dar forma ao que vai ser apontado como um novo gênero. Dito de outra maneira, a partir daquela seção, do que vai se dizer dela e das outras que a seguem, inicia-se um processo de leitura/escritura do que virá a ser significado como crônica brasileira. Portanto, o espaço dedicado à crônica era o do folhetim que figurava no rodapé do jornal. E, vale lembrar, tratava-se de um espaço destinado a mundaneidades ou a eventos culturais. Com o tempo, seu espaço passa a ser outro - por exemplo, passa a ser no alto da página do jornal e ao lado do editorial ou, como ocorre hoje em dia, na página ao lado do editorial. Com o tempo, foi-se, pois, configurando uma outra forma de dizer.

Em suma, a crônica, - difícil de ser caracterizada, até porque Comun. Inf., v. 7, n. 1, p.34-46, jan./jun. 2004 
polimórfica, como o espaço a ela destinado -, vai tendo suas marcas fixadas a partir da forma como se a escreve, em confronto com o que seriam as marcas do local onde se instala: o jornal. Em outras palavras, a crônica vai sendo definida em oposição a algumas das ilusões características do discurso jornalístico.

São várias as ilusões que fundam, fundamentam e dão direção ao discurso jornalístico. Como em Mariani (1998) há um extenso e aprofundado estudo sobre o discurso jornalístico, irei sucintamente recuperar duas das ilusões desse discurso: a que diz respeito ao mito da informação e, atrelada a esta, a que diz respeito ao mito da comunicação. Como primeiro existe a própria fundação do jornal como instituição: informar seria seu objetivo. Com o segundo, a onipotência do sujeito (p.72). Melhor explicando, a ilusão da função informativa se apóia na ilusão da comunicação, na medida em que esta supõe o controle do dizer, o controle, por conseguinte, dos sentidos pelo sujeito. Aí reside a idéia de onipotência do sujeito. O que importa destacar, a partir de Mariani, é que esses dois mitos produzem o efeito de literalidade e de transparência dos sentidos, e que ambos colaboram no sentido de instaurar uma relação de verdade com a informação (conforme Mariani, "verdade-da-informação"), o que também produz uma relação de confiança para com o que é narrado.

A crônica, resultado de posições que atuam no domínio do literário e do jornalístico, se materializa no espaço discursivo jornalístico. A crônica é produto do discurso jornalístico, como já se afirmou; no entanto, nela não são trabalhadas as ilusões do discurso jornalístico, ao contrário. Se o discurso jornalístico se supõe objetivo, neutro, transparente, da crônica se aponta a subjetividade, a parcialidade e a polissemia. Aautoria, aí entendida como índice de interpretação, reforça essas ilusões.

O discurso jornalístico, à semelhança do discurso histórico, mascara a função-autor e o gesto interpretativo, não mediante a presença de uma metodologia e/ou de referências, como faz o discurso histórico, mas por meio de uma suposta autonomia dos fatos e dos acontecimentos. Já a crônica constrói um sítio de significação em que se traz a marca do autor assumindo, por meio dela, um gesto de interpretação. Autor é, no espaço cronístico, tomado como presença subjetiva. Ou melhor, funciona como "marca" de subjetividade.

Comun. Inf., v. 7, n. 1, p.34-46, jan./jun. 2004 
No discurso jornalístico, discurso que se quer distante daquele da não-objetividade, a ilusão da neutralidade é reforçada por uma escritura sem "eu" e também por uma ausência de opinião, já que "os fatos falam por si" (MARIANI, 1998, p. 62). E isso se dá, importa retomar, em função da imagem que se constrói sobre o jornal: aquele que informa. Em outras palavras, o discurso jornalístico se constrói na ilusão de informar um "fato", sendo esse dado como algo transparente a ser divulgado. Sem interpretação, sem autoria. Não é o que ocorre com a crônica.

Cabe agora um breve comentário sobre autoria. O que caracteriza a autoria, em Orlandi, é a "produção de um gesto de interpretação" (1996, p.97). Gesto de interpretação que "recobre não uma subjetividade, mas um lugar, uma posição discursiva" (p.69) e que, por conseguinte, independe de uma assinatura. É nesse sentido que podemos dizer que o discurso jornalístico não é um discurso sem autor, mas funciona como se fosse, em função da ausência de uma assinatura, dentre outros fatores. Já o discurso cronístico se apresenta como subjetivo não somente porque se tem um "eu" (que pode ou não se mostrar), não porque nele se apresentem "marcas" de opinião (o que também muitas crônicas podem ou não conter), mas principalmente em função da assinatura, que aí funciona conjugando princípio de organização, princípio de textualidade e, sobretudo, posse, entendida aí como criação.

Importa lembrar que não é apenas no discurso cronístico que se tem a assinatura. Os articulistas e comentaristas também assinam suas matérias. Estas são consideradas espaços de opinião e, vale destacar, desde seus primórdios a opinião se fez presente e atuante na imprensa. Isso se explica, segundo Mariani (1998:73), por uma das propriedades do jornal, qual seja a adequação ao imaginário ocidental da liberdade de opinião. A assinatura tem, contudo, nesses espaços, outra significação: indica uma interpretação legitimada, uma "leitura original" e não a posse como criação, como ocorre no espaço cronístico. Em outras palavras, a interpretação fica, no âmbito do jornal, a cargo dos articulistas e comentaristas, isto é, daqueles que têm no jornal o papel de opinar (MARIANI, 1998, p.73), logo, de administrar uma interpretação. E por ela também são responsabilizados. Mas sua "interpretação" não é tomada como marcada por uma subjetividade,

Comun. Inf., v. 7, n. 1, p.34-46, jan./jun. 2004 
antes segue a orientação da imagem que se faz do discurso jornalístico, qual seja da informação e, no caso dos comentaristas e articulistas, da explicação. Afinal, se a "imprensa deve desambigüizar o mundo" (MARIANI, 1998, p. 63), informar e explicar vão constituir duas facetas de um mesmo processo.

Antes de prosseguir, irei me deter um pouco mais na questão da assinatura. Foi dito que a assinatura funciona diferentemente na crônica e no artigo: neste implica legitimação do dizer; naquela, propriedade e criação. E o pseudônimo, que tanto comparece nas crônicas? Como funciona?

Foucault, em O que é um autor? (1997), diferencia nome de autor de nome próprio. Mais do que designar (função do nome próprio), o nome do autor teria na nossa cultura a função de servir de elemento classificatório, agrupando, selecionando, delimitando textos e opondoos a outros (p.44). Ainda em Foucault, lê-se:

"o nome de autor serve para caracterizar um certo modo de ser do discurso: para um discurso, ter um nome de autor, o facto de se poder dizer "isto foi escrito por fulano" ou "tal individuo é o autor", indica que esse discurso não é um discurso quotidiano, indiferente, um discurso flutuante, passageiro, imediatamente consumivel, mas que se trata de um discurso que deve ser recebido de certa maneira e que deve, numa determinada cultura, receber um certo estatuto"( $\mathrm{p}$. 45).

O nome de autor tem como efeito, portanto, destacar, retirar da condição hodierna um "modo de ser do discurso", singularizar, individualizar alguém. Pensando a assinatura por meio de um pseudônimo na crônica, julgo que se tem com o pseudônimo a função classificatória de que fala Foucault. É o pseudônimo que servirá como elemento de identificação e de agrupamento. A assinatura como tal, isto é, por meio de pseudônimo, confere a marca de autoria. Mas, por outro lado, o pseudônimo tensiona a função do nome de autor. Ou seja, agrupa, mas sob um "pseudonome", aquilo que releva do espaço comum, e, com isso, joga com a função designatória do nome: apaga o que designa. Marca e mascara ao mesmo tempo. Expõe a ilusão do nome, na medida em que sustenta $o$ anonimato da figura do autor. $E$, assim, cumpre-se a função do discurso literário - ter um autor -, mas se oculta seu nome no pseudônimo. Indo mais adiante, o pseudônimo joga com a

Comun. Inf., v. 7, n. 1, p.34-46, jan./jun. 2004 
sacralização do nome do autor.

Voltemos à distância entre ciência e literatura para dar continuidade à reflexão sobre o espaço da crônica no discurso jornalístico. Se as cisões de que falam Pêcheux e Orlandi levaram à instituição de um discurso da ciência com base em critérios como "verdade", "neutralidade", "imparcialidade", cujas raízes podem ser encontradas no discurso da lógica matemática, não se pode esquecer que o discurso jornalístico também opera com tais noções; no entanto, não se postula como um discurso da ciência. O discurso jornalístico é um discurso urbano, produto de um tempo já capitalista e que objetiva o leitor comum. Não se pretende como restrito a parceiros de laboratórios. Mas é um discurso que trabalha a domesticação dos sentidos e que, assim, vai se aproximando do paradigma da ciência. Ainda uma observação antes se continuar: é preciso considerar os dois paradigmas - da ciência e da não-ciência-como um continuum. É nesse sentido que se aproxima, aqui, o discurso jornalístico do paradigma da ciência, mas sem tomá-lo como tal.

No que tange à tensão que o discurso cronístico promove no discurso jornalístico, esta se dá por ser a crônica um dos espaços nos quais as ilusões que fundamentam o discurso jornalístico se diluem, onde os sentidos deslizam. Cabe destacar, aqui, a crônica como "um dos espaços", já que há outros espaços, como é o caso das charges e caricaturas que, como nota Mariani, "correspondem a um lugar privilegiado que de dentro do discurso jornalístico faz deslizar sentidos".

Dito de outra maneira, se o discurso jornalístico opera com a ilusão da estabilização dos sentidos (linguagem transparente, sentido literal, fato narrado sem interferências, neutralidade, etc.), é o espaço cronístico um dos lugares em que esses são explorados, tensionados, problematizados. A crônica (assim como a charge e as caricaturas) trabalha os sentidos expostos no jornal. São nesses espaços que se tem a ironia, que desmonta o dito; a piada, que o ridiculariza; a paródia, que expõe a possibilidade do sentido outro. São nesses espaços em que se "estranham" os diversos dizeres. Se o jornal se preocupa com o "furo" ou com o "fato", é no espaço cronístico que se pode encontrar o risível ou o "estranhável" dessas preocupações. Com a crônica, o "fato" pode não apenas ser exposto ao equívoco como também ser outro. E não somente isso. A crônica também promove uma outra Comun. Inf., v. 7, n. 1, p.34-46, jan./jun. 2004 


\section{4}

tensão: sobre o cotidiano no jornal.

No jornal, como é sabido, encontram-se matérias diversas que dão conta de questões do dia-a-dia, de ordem, por exemplo, política, social, artística, e de dimensão tanto nacional quanto internacional. $\mathrm{O}$ cotidiano, que aí se insere sob a forma de atualidade e novidade, é trabalhado, em função dos mitos e ilusões apontados, como "fato", como "verdade"; indo mais longe, como "real". A relação instaurada com o leitor é aquela da verdade-da-informação, de confiança na informação. O jornal se funda e garante seu dizer a partir dessas premissas. Não há espaço para o equívoco em relação ao que se toma como fato, não há espaço para o fato ser outro. Citando Mariani:

"cabe ao discurso jornalístico organizar e ordenar cotidianamente os acontecimentos, de modo a mostrar que pode haver mais de uma opinião/explicação para o fato em questão, mas nunca fato diferente do que foi relatado" (p.61).

A crônica, como dizem cronistas e críticos literários, também tem como material o cotidiano. No entanto, este aí se insere de outro modo. Em primeiro lugar, o cotidiano não significa, no espaço cronístico, necessariamente atualidade. A crônica não tem compromisso com o último acontecimento, seja ele da ordem que for. Em segundo lugar, a crônica não tem também a pretensão da novidade. A repetição, a reelaboração de um dizer ou de um tema pode vir a constituir diversas crônicas de um mesmo autor, em um mesmo período ou não. Ademais, pode ocorrer de uma mesma crônica ser republicada em época diferente.

A crônica lança mão do objeto cotidiano, trabalha, pois, com o objeto do jornal, mas ressignificando-o, apresentando outros sentidos ao mundo. Não trabalha a "desambigüização" do mundo. E também não se pode esquecer a esteticização do cotidiano que a crônica engendra, na medida em que também se configura como um discurso literário no discurso jornalístico. ${ }^{6}$

Enfim, a crônica discursiviza o cotidiano, diferentemente dos outros espaços jornalísticos, instaurando a possibilidade de um equívoco no "fato", no "acontecimento" jornalístico. Não almeja a "verdade", não pressupõe o "real", apesar de trabalhar questões da ordem do cotidiano. Não pretende informá-lo nem explicá-lo. Essa é a sua função no jornal.

Comun. Inf., v. 7, n. 1, p.34-46, jan./jun. 2004 
Nasceu vinculada ao discurso jornalístico, é seu produto. Um produto que tensiona seu fazer.

\section{Abstract:}

In this text the author analises the role of columns (chronicle) in dayly newspaper as a locus of tension with journalistic informations. The columnism is a way to show the illusion of considering journalistic discourse in its objectivity and relation to the truth.

Key-words: dayly columns, journalistic discourse, truth

\section{Referências}

BENJAMIM, W. Obras escolhidas: magia e técnica, arte e política, 3a. ed., 1o. vol., SP: Brasiliense, 1987.

CANDIDO, A.. "A vida ao rés-do-chão". In CANDIDO, A. [et al.]. $A$ crônica: o gênero, sua fixação e suas transformações no Brasil. SP, Campinas: Ed. UNICAMP, Campinas, RJ: Ed. Fundação Casa Rui Barbosa, 1992

COSTA LIMA. Sociedade e discurso ficcional. RJ: Ed. Guanabara, 1986.

FOUCAULT, M.. O que é um autor? Lisboa: Ed. Passagens, 1997. . A ordem do discurso. $4^{\mathrm{a}}$ ed. SP: Loyola, 1998.

MARIANI, B. $O P C B$ e a imprensa: os comunistas no imaginário dos jornais, 1922-1989. RJ: Revan, Campinas: Unicamp, 1998.

MEDEIROS, V. Dizer a si através do outro: do heterogêneo no identitário brasileiro. Tese de doutorado, UFF, 2003.

NEVES, M. N. "Uma escrita no tempo: memória, ordem e progresso nas crônicas cariocas". In: CANDIDO, A. [et al.]. A crônica: o gênero, sua fixação e suas transformações no Brasil. Campinas: ed. Unicamp, RJ: ed. Fundação Casa Rui Barbosa, 1992.

ORLANDI, E. Terra à vista: discurso do confronto: velho e novo mundo. SP, Cortez; Campinas, SP: Unicamp, 1990.

. Interpretação, $2^{\mathrm{a}}$ ed., Petrópolis, RJ: Vozes, 1996.

. Discurso e texto, SP: Pontes, 2001.

PÊCHEUX, M. "Ler o arquivo hoje". In ORLANDI, E. (org.) Gestos de Leitura. Campinas, SP: Ed. Unicamp, 1997.

RESENDE, B.. (org.) Cronistas do Rio, $2^{\mathrm{a}}$ ed., RJ: José Olympio, 2001.

Comun. Inf., v. 7, n. 1, p.34-46, jan./jun. 2004 


\section{Notas}

1 Este artigo é fruto de um recorte promovido em um capítulo denominado "Discurso cronístico" - de minha tese de doutoramento (Medeiros, 2003).

${ }^{2}$ Conforme Benjamim, essa forma, embora com raízes antigas, só vem a se destacar com a consolidação da burguesia (1987, p. 202).

${ }^{3}$ Tal afirmação tem suas raízes em Cândido, A. (1992): "A crônica não é um gênero maior".

${ }^{4}$ Termo de Pêcheux, 1997.

${ }^{5}$ Sobre a noção de autoria, gostaria de destacar que na tese (Medeiros, 2003) da qual este artigo é fruto, ela é trabalhada com vagar. Aqui, importa dizer que está sendo tomada como forma histórica.

${ }^{6}$ Vale registrar que é somente na década de 1950 que a crônica passa a ser discutida como gênero literário (Resende, 2001).

Comun. Inf., v. 7, n. 1, p.35-46, jan./jun. 2004 